\title{
Learning Calculus through Application
}

\author{
Zelu Wang, Yuquan Sun \\ School of Automation Science and Electrical Engineering, Beihang University, Beijing100191, China \\ wzlfirework@sina.com, sunyq@buaa.edu.cn
}

\begin{abstract}
Learning to meet practical needs is not only an important purpose of study, but also a great method of study, which is also suitable for a better learning of Calculus. As we all know, many students don't have enough interest and motivation to study Calculus, because of their lacking cognition of its practical use as well as the object fact that Calculus logical derivation is too abstract and complex to understand. What is worse, some of those students even lose their confidence to learn Calculus well and give it up in the end.

Learning Calculus through application may be a great way to cope those problems, for one thing, it is helpful for students to have a better understanding of the related concepts and essential methods, for another, it helps them to link Calculus to other engineering mathematics, building knowledge structure of engineering mathematics .

Index Terms - Calculus, Learning by using, Economics, Management
\end{abstract}

\section{Introduction}

The first day we entered into a primary school, we began to study mathematics, however, we may still feel difficult to study engineering mathematics analysis when we entered college.

Although the teaching process is accelerated significantly in the college, Mathematics, which is abstract and boring, still makes many students prohibitive to study it. The Ignorance of the visualization of the Calculus teaching, which leaves the course hard to study, and the lack of attention on its practical uses, which makes many students incident of its practical uses , are among those main reasons why we students lack of interest in this course . [1].

However, the same course in Beihang University seems a little bit different, while meeting students' conscious of" learning to meet practical needs". Our teaching team pays much attention to the practical application, with research-oriented teaching reform, encourages students initiatively to take part in the mathematical discovery or creation activities: 1) Whether Euler's constant is rational or irrational? 2)Discuss a completeness about algebraic structure, set links among Archimedes' property, dense property, additive commutative law, associative law of addition, multiplication commutative law and associative law; 3) Using real number properties of complete theorem shows the comprehension between the limit definition and the real continuity; 4) Illustrate for the application for sequence and the sequence limit; 5) Further thinking and application on the principle of compression mapping; 6)Using Taylor's theorem to calculate the extrapolation for the second derivative; 7) Studying better ways to conquer Taylor theorem to find local approximation; 8)More accurate research methods for identifying the positive series converges; 9)Further thinking on Canchy theorem, find examples to persuade Canchy theorem in our midst; 10) A number of calculus model in the field of application, such as economy, biology, astronomy etc.; 11) Discuss some certain parts of the teaching material and solution methods theorem [2]. Even though these theories are really rich, however, as they are mainly confined to the engineering mathematics analysis content, we still don't have a clear mind on how to use them in the future study.

The application of Calculus's in economic, biology and astronomy inspires me a lot. In the next section, we will summarize the calculus's application from the book named Introduction to Economic and Management, which is the compulsory course in Beihang University, aiming to cultivate students' interdisciplinary talents. In the third section will give a conclusion and tell my experience about the application of calculus to economic management.

\section{Application in Introduction to Economic and Management}

The word "Introduction" in the book named "Introduction to Economic and Management" shows that it seems just for the basic usage, however when you browse the whole courseware, you may find some calculus points, these points not only make a widely application on calculus theory, but are very helpful to understand the essence of calculus.

\section{A. Application in introduction to economic}

Introduction to Economic and Management course include two parts: one is the introduction to economic and the other is introduction to management. Combined with Beihang's feature, First part gives general principles of management under the background of industrial enterprise. Because of this, the optional quantity is the main factor.

Production decision goal is to maximize profits, as Figure 1 shows, profits come from balance of sales revenue and total cost .



Figure 1 Single variety product's quality decisions 
As Figure1 shows, sale revenue is based on the sales quantity, we call it $S(x 1)$; Meanwhile, total cost is rely on its production, we call it $\mathrm{C}(\mathrm{x} 2)$, under the demand principle, we will easy get $\mathrm{x} 1=\mathrm{x} 2=\mathrm{x}(\mathrm{x}$ instead, stand for sales quantity and production), then the profit function is $\pi(x)=S(x)-C(x)$.

Just as the equation shows below, under the profit maximization purpose, through the way of first derivation on profit function, we can get the optimal $\mathrm{x}$,

$$
\pi^{\prime}(\mathrm{x})=\mathrm{S}^{\prime}(\mathrm{x})-\mathrm{C}^{\prime}(\mathrm{x})=0
$$

$S^{\prime}(x) \cdot C^{\prime}(x)$ stand for the marginal revenue and marginal cost respectively which represent the increasing amount on revenue and costs because of the increasing on unit volume .

The reason why we should arrange production inputs reasonably is profit maximization purpose. The optimal factors of production can be reflected such clearly through the isoquant and that of isocost curve. Production of products always requires investment, which is commonly known as human, finance and property. In the most simple way to show in Cobb-Douglas production function, output $\mathrm{Y}$ is rely on the input factor- capital $\mathrm{K}$ and labor $\mathrm{L}$ :

$$
Y=A K^{\alpha} L^{\beta}
$$

A stands for the technological level, $A>0 \alpha, \beta>0$.

We found that $\mathrm{Y}$ is an increasing function of $\mathrm{K}$ and $\mathrm{L}$, and the isoquant curve is a intersecting line between specific quantity $\mathrm{Y}^{*}$ and production function $\mathrm{Y}=A K^{\alpha} \mathrm{L}^{\beta}$. As Figure 2 shows, because of the production function's increasing characteristics, isoquant may be different.

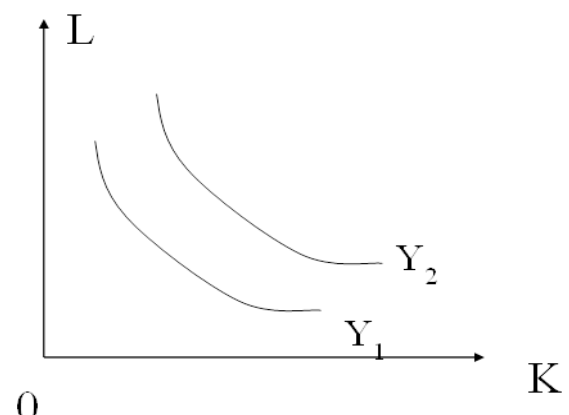

Figure 2 isoquant curve

Similarly, as Figure 3 shows through cost function $\mathrm{C}=\mathrm{PL} \cdot \mathrm{L}+\mathrm{PK} \cdot \mathrm{K}$ the isocost curve can also be drawn. PL, PK stand for the price of labor force, as PL $>0, P K>0$, the cost function is also an increasing function. When PL and PK are both constant, the cost function which will be only rely on the two variables $\mathrm{L}$ and $\mathrm{K}$, can be described as a plane. Therefore, isocost curve is a simply straight line with a different position because of the $\mathrm{K}$ and $\mathrm{L}$ factors.

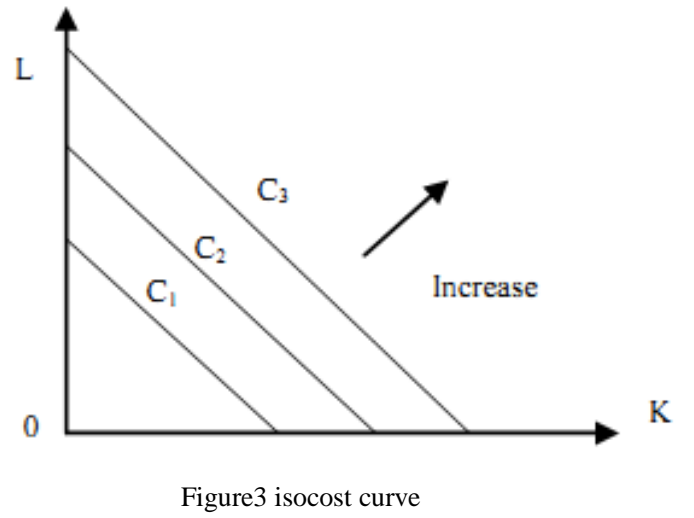

Combine Figure 2 and Figure 3 together, just as Figure 4 shows, the point which isoquant and isocost curve got tangency decides the optimal input in factors of production. In the condition of a given output, this point of tangency shows the minimum cost.

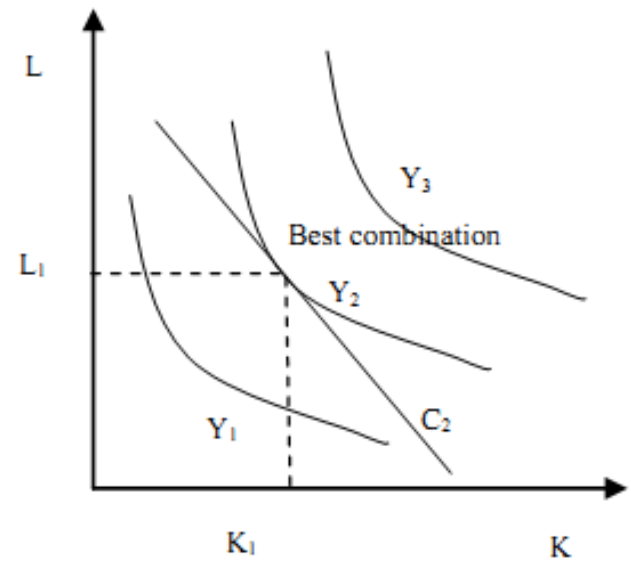

Figure 4 optimal input in factors of production

\section{B. Application in introduction to management}

Now let's talk about the second part: introduction to management which also include basic economic theory such as market mechanism analysis and engineering economics.

The main reason to study market mechanism analysis is to find a balance point in supply-demand relationship, as a result, the concept of elasticity and its calculation and application becomes the core item. The price elasticity of demand, for example, reflect the extent to which demand response to price changes. The definition is:

Price elasticity of demand $=$ demand rate of change/price rate of change:

$$
\mathrm{E}=(\mathrm{dQ} / \mathrm{dP}) \cdot \mathrm{P} / \mathrm{Q}
$$

$\mathrm{P}$ stands for price, $\mathrm{Q}$ demands quantity, $\mathrm{E}$ is the price elasticity of demand. Nowadays, the price elasticity of demand has been widely used for the analysis or the estimate product price, quantity and price decision.

Calculus's application in engineering economics is much more widespread, for example, continuous rate just comes out 
of the ultimate limit of computation on the real interest rate and nominal interest rate. If hypothesis i means real interest, $r$ means nominal interest rate, $\mathrm{m}$ means interest period, then the real interest rate comes:

$$
i=\left(1+\frac{r}{m}\right)^{m}-1
$$

When $\mathrm{m} \rightarrow \infty$, i equals to continuous rate.

$$
i=\lim _{m \rightarrow \infty}\left(1+\frac{r}{m}\right)^{m}-1=\lim _{m \rightarrow \infty}\left[\left(1+\frac{r}{m}\right)^{\frac{m}{r}}\right]^{r}-1=e^{r}-1
$$

Actually, the calculation on payback period and internal rate of return, as well as sensitivity analysis, all of them come out from approximate calculation with monotonicity of a function. So in order to improve the calculation accuracy, it's necessary to shrink calculation step, which is the concept of calculus.

\section{Thinking about Calculus}

Just from Introduction to Economic and Management this one course, I may forecast that calculus is really helpful through the way to future study, follow my teacher Yuquan Sun's words, engineering mathematics analysis is the core course in our college life both for the study and for the application. As Nengsheng Qian said, calculus, one of the greatest discoveries in 17 th century has already become the most powerful tools to help people understand and reform the nature. There is no exaggeration to say that Not mastered calculus cannot learn and master any one of modern natural science, engineering and management science [3]. Therefore, we must study Calculus well.
Even though, I just teach myself on introduction to economic and management courses, through the figure and data, I find it is not difficult to understand, and realize the advantage from foreign calculus teaching reform. From the instance of Harvard Calculus and The Rule of Four-let the calculus shows in figure, data, symbol and words [4-5] Meanwhile, perceptual materials and vivid situation and a lot of fun to calculus study and change it from abstract to intuition [6]

Calculus is an important basic course in many engineering colleges. Different teachers have different ways to show their knowledge, as a whole, learning through application makes study much more effective, however, only rely on teachers will make no sense, students are playing important roles. From diversity on students' background, teachers could have a large range to choose. Because of the collaboration, our teaching materials may become plentiful and useful.

\section{References}

[1] Chen Yue. Talk about Calculus from the perspective of history. STUDIES IN COLLEGE MATHEMATICS, 2005, 8(6): 47-50, 54

[2] YANG Xiao-yuan, LI Shang-zhi, SUN Yu-quan, XUE Yu-mei, YANG Zhuo-qin, YANG Yi-chuan. Opening Teaching and Practice for Mathematical Analysis. COLLEGE MATHEMATICS, 2011, 27(3): 1-6

[3] Qian Neng-sheng. A brief history of Calculus and its implications. JOURNAL OF WUYI UNIVERSITY (Natural Science Edition), 2002, 16(1): 75-78

[4] Louis M Friedler, Edward F Wolff. What's New with Reform Calculus in the US. STUDIES IN COLLEGE MATHEMATICS, 2012, 15(1): 1-5

[5] WANG Na. Approach the calculus with the natural language-Taking Calculus written by James Stewart as case. Journal of Shenyang Institute of Engineering( Social Sciences), 2011, 7(3): 418-421

[6] LUO Min-na. Calculus teaching based on mathematical history. Journal of Shenyang Normal University (Natural Science), 2011, 29(4): 578-580 